\title{
Teorias e práticas no campo do acompanhamento terapêutico
}

\author{
Ítor Finddli Júnior - UnivesidadeSãoFranisco, Itatiba, SãoPaulo, Brasil
}

\author{
Antúnez, A. E . A. (2011). Acompanhamentoterapâtica casosdínicoseteerias São Paulo: Casa do Psicólogo.
}

0 acompanhamento terapêutico (AT) trata-se de uma modalidade de atendimento psicológico em que 0 local do trabalho é justamente o contexto do paciente. Certamente que inserido nesse contexto, 0 acompanhante terapêutico (profissional) atua de maneira diferenciada em diversos aspectos. Nessa direção, o livro, organizado por Andrés Eduardo Aguirre Antúnez, denominado "Acompanhamento terapêutico: casos clínicos e teorias" apresenta esse campo de difícil definição, tamanha sua diversidade e amplitude. Essa indefinição, segundo Luciana ChaúBerlinck, está presente na maior parte dos aspectos dessa atividade; por outro lado, ela esclarece que a publicação desse livro, apresenta uma série de possibilidades, parâmetros e reflexões acerca dos acompanhantes terapêuticos, pacientes, teorias e aspectos éticos dessa atuação.

A obra foi organizada em quinze capítulos escritos por especialista da área de AT de diferentes formações clínicas. Sua leitura é recomendada para os interessados por esse campo, estudantes e profissionais clínicos que desejam refletir sua atuação nos contextos privados, sejam eles institucionais ou particulares. $\mathrm{O}$ primeiro capítulo, escrito por Andrés E. A. Antúnez, Kleber D. Barreto e Gilberto Safra, introduziu o AT como um modelo de intervenção que ocorre no cotidiano de uma pessoa. Nesse sentido, a proximidade do acompanhante terapêutico o faz testemunha de que 0 adoecimento pode ser visto não só como decorrente de dinâmicas intrapsíquicas, mas também do mal-estar no mundo social e cultural. Os autores apresentaram um relato de atendimento de Minkowski, cujo paciente tinha 66 anos e foi acompanhado 24 horas por dia, durante sessenta dias. Na apresentação, os autores fazem importantes considerações sobre a temporalidade e a importância do futuro, como um elemento de expansão e sentido para o cotidiano.

Escrito por Carla A. B. Gonçalves, o segundo capítulo contextualizou o AT na Reforma Psiquiátrica. Importantes considerações foram feitas a respeito da loucura, sua inserção e aceitação social. D estacou-se na medida em que a Reforma Psiquiátrica extinguiu a loucura como situação marginal, por meio dos princípios de inclusão, solidariedade e cidadania. O AT possuiu uma atuação específica para esse paradigma, sendo essa atuação produto da reforma. Trata-se de uma produção de valor social que auxilia e transforma a exclusão secular vivida por esses pacientes. A autora também articulou um caso em que a produção cultural e social produziu sentido de existência. Destacou, ainda, a importância da flexibilidade do terapeuta para se adequar à demanda do paciente, a construção de um projeto individualizado com sentidos que proporcionaram ao acompanhado exercer sua contratualidade.

No terceiro capítulo, o autor Maurício Porto relacionou a formulação de Foucault sobre o biopoder com 0 processo de intervenções e controles regulatórios para a produção da vida. Nessa reflexão, delineou a regulação da vida de um paciente por meio de um hospital psiquiátrico. É 0 acompanhar a evolução da doença e incitar no doente uma saúde que, individualmente, 0 recuperasse, devolvendo-o ao convívio regular na norma. Destacou a tendência na sociedade de controle de sempre expandir o território e incluir as populações em seus processos de gestão da vida, por meio da produção de um cotidiano que dilui fronteiras sociais. E justamente nessa condição é que 0 AT investe em nomadismo e fornece segurança ao acompanhado por estar inserida no próprio sistema de sua vida em sociedade.

Para o quarto capítulo, de Julio C. R. de O liveira e Arthur Tufolo, e o quinto, de Carolina G. de Batista, foi mencionada a importância da proximidade do acompanhado e o processo de envelhecimento em estudos de caso. Para a proximidade, os autores consideram a distância e 0 uso de uma lenta aproximação para permitir a intimidade. Isso auxilia no intenso medo sobre as alterações do ambiente causadas por um acompanhante terapêutico. Para 0 envelhecimento, essa mesma situação é relatada. A autora relacionou, ainda, o processo de exclusão da loucura com a velhice e destacou o papel do AT como recurso em que acompanhantes e acompanhados reinventam um modo de se relacionar e estar no mundo, sendo o acompanhante um intérprete ativo que realiza ações possibilitadoras de encontros, movimento e atitudes.

No capítulo seguinte, por Ananéia M. Bezerra, foi apresentada importância do trabalho de um acompanhado por uma equipe de acompanhantes. Nele foram dialogadas implicações, como a mudança de membros da equipe, as diferenças do sexo do acompanhante e a visão do outro profissional. Essas situações trouxeram pontos importantes para 0 trabalho com AT nas dinâmicas interpessoais e 0 
processo de reduçäo de crises. Ainda para a reduçào de crises, o capítulo sétimo, de Maria S. Logatti, caracterizou o AT como um apagador de incêndios e abordou sua atuação na resolução de crises e problemas mentais específicos. A autora apresentou um estudo de caso, no qual relatou a importância do papel dos outros moradores da casa do acompanhado, a necessidade da medicação de base, a busca de atividades para enriquecer a vida social/ funcional e 0 exercício da autonomia pela compreensão das limitações do paciente.

Considerando a importância do AT e 0 acompanhamento de pessoas com deficiência, Carolina Y. Fujihira organizou o oitavo capítulo e relacionou a inserção social desses indivíduos e as necessidades que surgem para acompanhamento. A partir de uma vivência específica de dois acompanhados com deficiência intelectual, a autora dialogou sobre invisibilidade social vivenciada em aspectos como a sexualidade, o cumprimento de normas sociais exigidas para determinados contextos, a identidade de um indivíduo com deficiência, entre outros. Por fim, concluiu que a necessidade de apoio não significa impedimento, e sim possibilidade.

Em dois estudos de caso, o capítulo nono, escrito por Ricardo T. de D eus, e o décimo, por Alexandre S. Piné trouxeram pontos comuns sobre 0 amadurecimento. Para o nono, tratou-se de uma paciente psicótica de 28 anos que possuía o sentimento de não estar sincronizada com sua idade biológica. Nesse estudo de caso, o autor utilizou a clínica Winnicottiana para destacar a tendência inata ao amadurecimento e a presença contínua de um ambiente facilitador que forneça ao indivíduo cuidados suficientemente bons para retomar 0 seu processo de amadurecimento. A necessidade de temporalização, retorno aos aspectos da realidade e diminuição dos sintomas persecutórios foram essenciais na atuação do AT. Intervenções semelhantes nessas três dimensões também foram mencionadas no estudo de caso do capítulo décimo, que tratou de um paciente de 65 anos, vítima da ditadura militar brasileira. 0 autor não somente retratou uma imobilidade física, mas mental nos aspectos do passado, das ideias das confluências da vida e dos afetos. A utilização de elementos da realidade foi um recurso bastante utilizado no tratamento. Em especial, esse capítulo descreveu com profundidade os limites enfrentados pelo acompanhante e sua vontade de desistir do processo.

Saindo da temática dos estudos de casos, 0 décimo primeiro capítulo, escrito por Caroline O. M. Vidal e Kleber D. Barreto, analisou um conto de Guimarães Rosa à luz do AT. Em sua análise, os autores descreveram que a loucura não exclui a condiça humana tundamental de acompanhar e ser acompanhado, a possibilidade de estar com o outro, de sentir com 0 outro. E ponderaram que a ética da clínica do acompanhar não está em evitar experiências de sofrimento, mas sim em criar possibilidades de transformar tais vivências, usar o que nelas se viveu como potência, como marcha.

Reflexões sobre a experiência de um AT com um adolescente foram descritas no décimo segundo capítulo, por Marcelo S. Cruz. Esse estudo de caso apresentou um jovem de 17 anos, adotado quando criança e suas dificuldades enfrentadas na vivência com os pais. 0 autor descreveu, para essas vivências, sentimentos de vazio e necessidades emocionais pouco reconhecidas ou atendidas devido à dificuldade de apropriação do filho. Havia um sério conflito de valores inalcançáveis que confirmavam a insuficiência do jovem, que ao mesmo tempo agredia e procurava incorporá-los/ atingi-los. 0 abuso de substância foi relatado como um suprimento na suposta falta de investimento e a experiência de vazio vivida por esse paciente.

Em Clariceando e o AT, a autora do décimo terceiro capítulo, Daniela D. Torre, encontrou em Clarice Lispector um formato literário para aproximar acompanhante e acompanhado. Nesse relato de caso, a autora abriu fronteiras para que 0 sofrimento humano entrasse em movimento. Nesse encontro, o AT foi um parágrafo vivo que antecedeu a morte da paciente, dois anos mais tarde. A paciente era uma viúva, filha de intelectuais, nascida na década de 40 , cujo acúmulo de coisas, a ausência do outro, o cenário abandonado de uma casa e as alterações de peso do seu corpo denotaram um profundo sofrimento e uma busca incansável por si mesma. O AT, nesse caso, possibilitou 0 estabelecimento da integração do sdf, perdido ao meio da poeira e da ausência do outro.

No penúltimo capítulo, Sheila de Marchi expôs uma experiência de AT numa atividade ocupacional artística com pacientes de baixa renda com transtornos psiquiátricos. Tratou-se de uma convivência fora da instituição de tratamento, em um projeto elaborado em parceria com o Museu de Arte Moderna de São Paulo. Nessas vivências, a autora descreveu o valor da experiência artística na proximidade com as fantasias desses pacientes. Destacou-se a importância do acompanhante em se colocar ao lado do acompanhado, durante 0 percurso e até mesmo na própria atividade, sendo os resultados um fortalecimento do compromisso e autonomia nas atividades, além do reconhecimento pelo trabalho artístico e melhorias no relacionamento familiar.

E por fim, no último capítulo, Tânia Possani apresentou algumas passagens clínicas e ponderou a 
empatia como a condição que melhor descreve 0 trabalho do AT. Nessas passagens, destacou a mutualidade da empatia não somente por parte do acompanhante. Além dessa condição, trouxe a importância da confiança e a compreensão da comunicação do outro. A autora descreveu que há algo que é comunicado que está além do discurso representacional, e também articulou conceitos para um posicionamento ético nos atendimentos, como corpo, corporeidade, empatia e estética.
Considera-se que a publicação do livro "Acompanhamento terapêutico: casos clínicos e teorias" preenche uma importante parte da lacuna no campo de publicações nacionais dessa modalidade de atendimento. Esse importante pedaço está relacionado à tamanha diversidade de situações, teorias e práticas organizadas nos capítulos. Os textos apresentam reflexões pertinentes e muito bem embasadas e fornece ao leitor um referencial de ações para um AT.

Sobre 0 autor:

Ítor Finotelli Júnior é psicólogo clínico, mestre e doutorando pelo Programa de Pós-Graduação StridoSensu em Psicologia da Universidade São Francisco do Campus Itatiba.

Contato com 0 autor:

Av. Barão de Itapura, 2294, sl.14 - Jardim Guanabara - CEP 13073-300. Campinas-SP.

E-mail: itor@psicoterapiasexual.com.br 